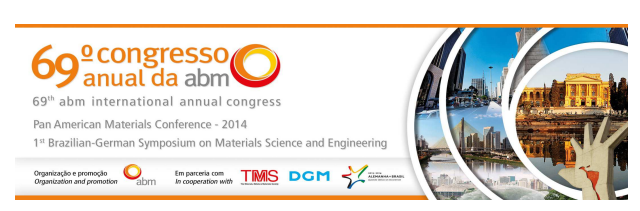

Tema: Engenharia de Superfície

\title{
INFLUÊNCIA DAS VARIÁVEIS DE PROCESSO E MEDIÇÃO NO ENSAIO DE PREECE EM ARAMES GALVANIZADOS (CLASSE B)*
}

Tiago Salzmann Vilela ${ }^{1}$

\section{Resumo}

No mercado de arames e cordoalhas galvanizadas para indústria de distribuição de energia elétrica, o ensaio de preece tem se tornado um requisito constante para assegurar a uniformidade da camada de zinco formada. Neste trabalho, foram estudados os efeitos da velocidade de galvanização tanto na uniformidade da camada de Zinco como na espessura da camada intermetálica de ferro-zinco. Também foi estudado o efeito do aquecimento após o processo de galvanização, observando o crescimento da camada intermetálica. Finalmente, serão mostradas as principais características de processo obtidas para garantir o atendimento ao ensaio de preece nos arames galvanizados (classe B) produzidos na Gerdau Cotia.

Palavras-chave: Preece; Revestimentos galvanizados; Zinco; Arame galvanizado.

\section{INFLUENCE OF PROCESS VARIABLES AND MEASUREMENT ON PREECE TEST ON GALVANIZED WIRES (CLASS B)}

\begin{abstract}
In the market of galvanized wire and stranded zinc-coated for electricity distribution industry, the preece test has become a constant requirement to ensure uniformity of the zinc layer formed. In this work, the effects of speed of galvanization on uniformity of the pure zinc layer and the thickness of the intermetallic layer of zinc-iron formed were studied. The heating effect was studied after galvanizing, observing the behavior of the intermetallic layer. Finally, we will show the main process characteristics obtained to ensure the preece test specification on galvanized wires (class B) produced at Gerdau Cotia.
\end{abstract}

Keywords: Preece test; Galvanized coatings; Zinc; Galvanized wire.

1 Engenheiro de Materiais, Assessor Técnico, Facilitador de Melhorias, Tecnologia de Processos, Gerdau Aços Brasil, Gerdau Cotia, SP, Brasil.

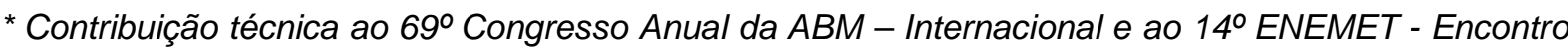
Nacional de Estudantes de Engenharia Metalúrgica, de Materiais e de Minas, 21 a 25 de julho de 2014, São Paulo, SP, Brasil.
} 


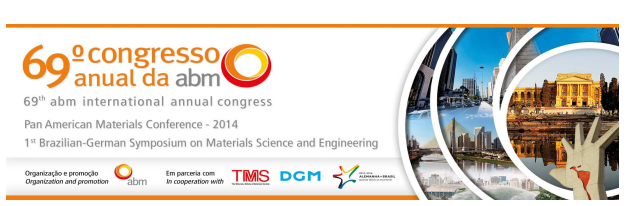

Alguns dos fatores citados acima, tais como velocidade da linha e tempo de imersão, foram estudados mais profundamente e ensaiados. Os demais fatores não foram detalhados nesse trabalho. Groesbeck e Walkup [4] avaliaram o efeito do tipo de camada de zinco na taxa de remoção do zinco da camada durante o ensaio de preece conforme Tabela 2.

Tabela 2. Perda de massa de $\mathrm{Zn}\left(\mathrm{g} / \mathrm{m}^{2}\right)$ em diferentes tipos de recobrimento [4]

\begin{tabular}{|c|c|c|c|}
\hline $\begin{array}{c}\text { Material/Processo } \\
\text { de galvanização }\end{array}$ & $\begin{array}{l}\text { Número de } \\
\text { imersões }\end{array}$ & $\begin{array}{c}\text { Perda de } \\
\text { peso }\left(\mathrm{g} / \mathrm{m}^{2}\right)\end{array}$ & $\begin{array}{l}\text { Média da perda de } \\
\text { revestimento }\left(\mathrm{g} / \mathrm{m}^{2}\right)\end{array}$ \\
\hline \multirow{7}{*}{ Arame de Zinco } & 1 & 51,9 & \multirow{5}{*}{ NA } \\
\hline & 2 & 56,1 & \\
\hline & 3 & 56,8 & \\
\hline & 4 & 58,9 & \\
\hline & 5 & 49,7 & \\
\hline & Total & 273,4 & NA \\
\hline & Média & 54,7 & NA \\
\hline \multirow{8}{*}{ Eletrodeposição } & 1 & 47,3 & \multirow{6}{*}{402,78} \\
\hline & 2 & 75,4 & \\
\hline & 3 & 74,8 & \\
\hline & 4 & 69,0 & \\
\hline & 5 & 68,4 & \\
\hline & 6 & 65,6 & \\
\hline & Total & 400,3 & NA \\
\hline & Média & 66,7 & \\
\hline \multirow{6}{*}{$\begin{array}{c}\text { Galvanização à } \\
\text { fogo }\end{array}$} & 1 & 41,8 & \multirow{4}{*}{241,05} \\
\hline & 2 & 63,5 & \\
\hline & 3 & 51,3 & \\
\hline & 4 & 39,4 & \\
\hline & Total & 195,9 & \multirow{2}{*}{ NA } \\
\hline & Média & 49,0 & \\
\hline \multirow{10}{*}{$\begin{array}{l}\text { Galvanizado e } \\
\text { recozido }\end{array}$} & 1 & 39,1 & \multirow{8}{*}{317,34} \\
\hline & 2 & 32,3 & \\
\hline & 3 & 31,7 & \\
\hline & 4 & 33,6 & \\
\hline & 5 & 36,6 & \\
\hline & 6 & 34,2 & \\
\hline & 7 & 31,7 & \\
\hline & 8 & 33,0 & \\
\hline & Total & 272,2 & NA \\
\hline & Média & 34,0 & NA \\
\hline \multirow{6}{*}{ Spray de zinco } & 1 & 74,1 & \multirow{4}{*}{357} \\
\hline & 2 & 76,6 & \\
\hline & 3 & 74,1 & \\
\hline & 4 & 67,1 & \\
\hline & Total & 292,0 & \multirow{2}{*}{ NA } \\
\hline & Média & 73,0 & \\
\hline
\end{tabular}

Groesbeck e Walkup [4] comparam a perda de zinco em cinco diferentes tipos de material/recobrimento: Arame de zinco, Eletrodeposição, Galvanizado à fogo, Galvanizado e recozido e Spray de zinco. Em cada um dos recobrimentos foi encontrada uma taxa de perda de zinco diferente. No processo de eletrodeposição a camada é formada praticamente por zinco puro. A observação desse experimento mostrou que a taxa de perda de massa por imersão foi a segunda maior de todas, apresentando resultado $66,7 \mathrm{~g} / \mathrm{m}^{2}$.

* Contribuição técnica ao $69^{\circ}$ Congresso Anual da ABM - Internacional e ao 14ํㅡㄹ ENEMET - Encontro Nacional de Estudantes de Engenharia Metalúrgica, de Materiais e de Minas, 21 a 25 de julho de 2014, São Paulo, SP, Brasil. 


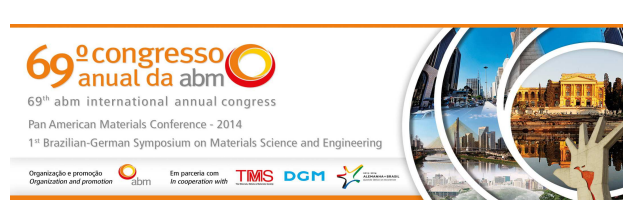

No processo de Galvanização à fogo, o zinco aquecido é arrastado pelo arame e também reage com o metal base formando uma camada intermetálica denominada Fe-Zn. Vemos que neste caso, a taxa de perda de massa por imersão foi de $49 \mathrm{~g} / \mathrm{m}^{2}$, sendo menor que no processo de eletrodeposição. Já no processo com galvanização e Recozimento, após o zinco ser depositado na forma metálica sobre o metal base, o arame volta a ser aquecido (recozido). O zinco por aquecimento continua a se difundir e aumenta a camada de intermetálico ao ponto de termos apenas Fe-Zn. Como essa camada intermetálica tem maior resistência ao ataque do sulfato de cobre, a perda é de apenas $34 \mathrm{~g} / \mathrm{m}^{2}$. Temos aqui a menor taxa de remoção da camada de zinco, mostrando que a camada intermetálica Fe-Zn oferece maior resistência no ensaio de preece.

De acordo com Mallet [5] as maneiras possíveis para aumentar a camada de Fe-Zn do arame são: aumentar o tempo de exposição do arame ao zinco (tempo de imersão na cuba) ou aumentar a temperatura do banho de zinco. Como a temperatura do banho de zinco já trabalha com $450^{\circ} \mathrm{C}$, aumentar a temperatura significa em deslocar a reatividade do zinco com o metal, podendo causar forte deposição de zinco nas bordas da cuba e danificar sua estrutura metálica.

Na figura 1 é mostrado o pico de reatividade do zinco com o ferro.

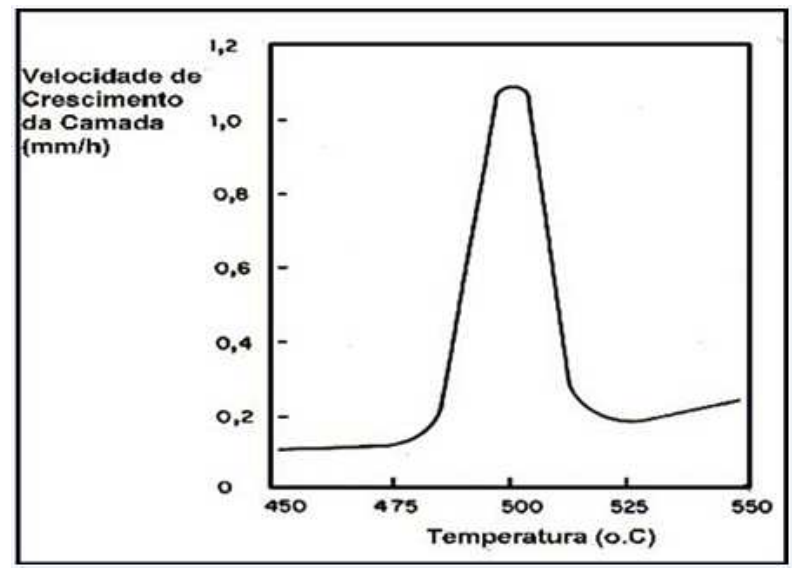

Figura 1. Pico de reatividade do zinco entre $475^{\circ} \mathrm{C}$ e $525^{\circ} \mathrm{C}$ [5]

Uma alternativa razoável para aumentar a camada de Fe-Zn é aumentar o tempo de exposição do arame ao zinco. Isso pode ser feito de algumas maneiras, tais como: aumentando o tamanho da cuba, reduzindo a velocidade do fio ou realizando mais de uma passada do arame pela cuba. Na figura 2, é possível ver o comportamento das camadas de zinco e Fe-Zn em função da velocidade. Em resumo, aumentandose a velocidade, têm-se camadas de zinco puro mais espessas, porém com redução de Fe-Zn.

\footnotetext{
* Contribuição técnica ao $69^{\circ}$ Congresso Anual da ABM - Internacional e ao 14ํㅡㄹ ENEMET - Encontro Nacional de Estudantes de Engenharia Metalúrgica, de Materiais e de Minas, 21 a 25 de julho de 2014, São Paulo, SP, Brasil.
} 

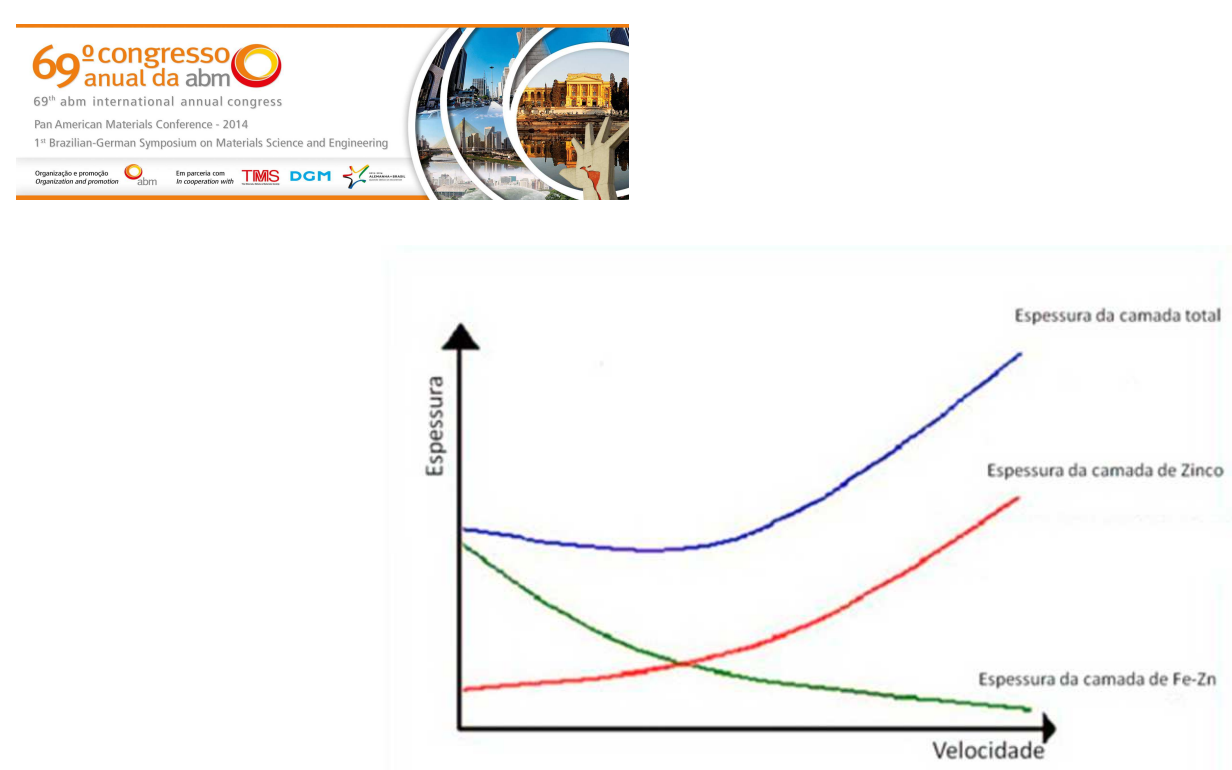

Figura 2. Relação do aumento da velocidade com as espessuras das camadas de Zn e Fe-Zn [5]

\section{MATERIAIS E MÉTODOS}

\subsection{Perfil das Camadas de Zn e Fe-Zn com a Velocidade na Galvanização}

Para avaliar a influência da velocidade nas camadas de $\mathrm{Zn}$ e Fe-Zn foi proposto um DOE (design of experiments) utilizando MINITAB® onde três grupos de arames com diâmetro 3,05mm (SAE1072) foram submetidos a velocidades de galvanização diferentes. O experimento teve início com velocidade de $10 \mathrm{~m} / \mathrm{min}$, aumentando de 5 em $5 \mathrm{~m} / \mathrm{min}$ até atingir $35 \mathrm{~m} / \mathrm{min}$. Para a raspagem do zinco foi utilizado o processo com vermiculita. Foi avaliada a gramatura dos arames produzidos $\left(\mathrm{g} / \mathrm{m}^{2}\right)$ bem como a espessura das camadas de $\mathrm{Zn}$ e Fe-Zn $(\mu \mathrm{m})$ através de metalografia da secção transversal do arame. As amostras foram envolvidas no papel alumínio, embutidas no baquelite ou resina e após isso o processo preparação comum (lixamento e polimento utilizando pasta de diamante). No ataque químico, utilizou-se nital $1 \%$, para revelar somente a estrutura da camada de zinco.

\subsection{Crescimento da Camada de Fe-Zn com Aquecimento}

Para avaliar o crescimento da camada de Fe-Zn após o processo de galvanização um conjunto de arames com diâmetro de $3,05 \mathrm{~mm}$ foi submetido a aquecimento em mufla e mantido por aproximadamente 300 segundos. Após esse tempo foram realizadas metalografias para avaliar a relação das camadas de zinco e Fe-Zn antes e após o aquecimento. Na figura 3 pode ser visto a mufla e a posição dos arames.

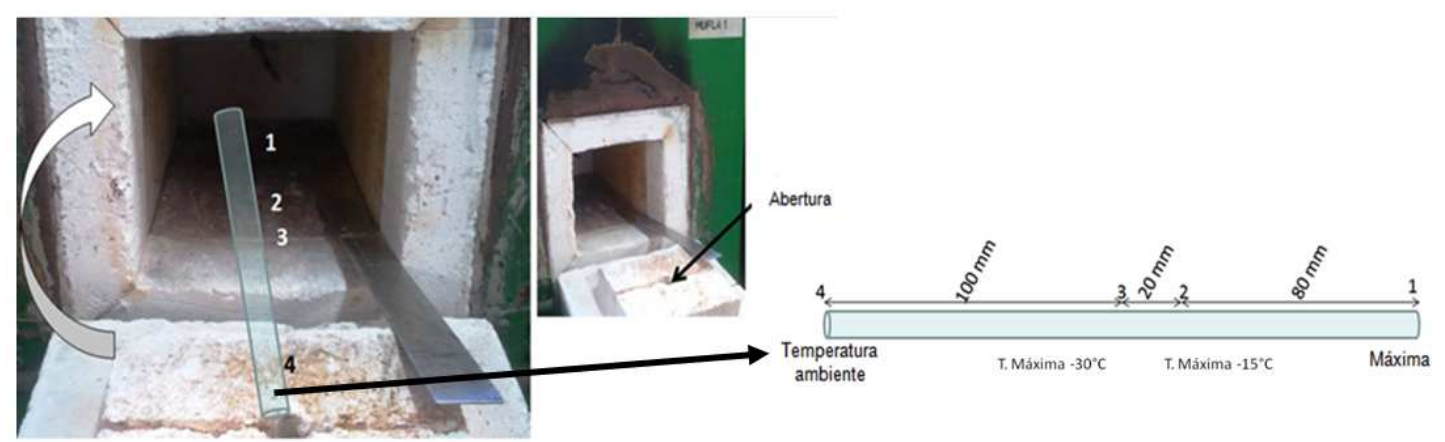

Figura 3. Mufla utilizada no aquecimento dos arames e as medições de temperatura em cada ponto

\footnotetext{
* Contribuição técnica ao $69^{\circ}$ Congresso Anual da ABM - Internacional e ao 14ํㅡㄹ ENEMET - Encontro Nacional de Estudantes de Engenharia Metalúrgica, de Materiais e de Minas, 21 a 25 de julho de 2014, São Paulo, SP, Brasil.
} 


\subsection{Uniformidade da Camada de Zinco nas Etapas do Processo de Galvanização}

Para verificar a existência de algum ponto ou mecanismo específico que pudesse deslocar a camada de zinco do arame após saída da cuba, foram coletadas amostras em diversos pontos da linha de galvanização. A velocidade da linha foi mantida em $20 \mathrm{~m} / \mathrm{min}$ e subitamente o processo foi interrompido. Nesse momento amostras foram coletadas nos pontos mostrados na figura 4 e avaliadas quanto a uniformidade da camada de zinco. Respeitou-se a posição do arame, efetuando uma marcação no sentido "sul" do mesmo. Posteriormente as amostras foram submetidas a metalografia da secção transversal para avaliar uniformidade da camada.
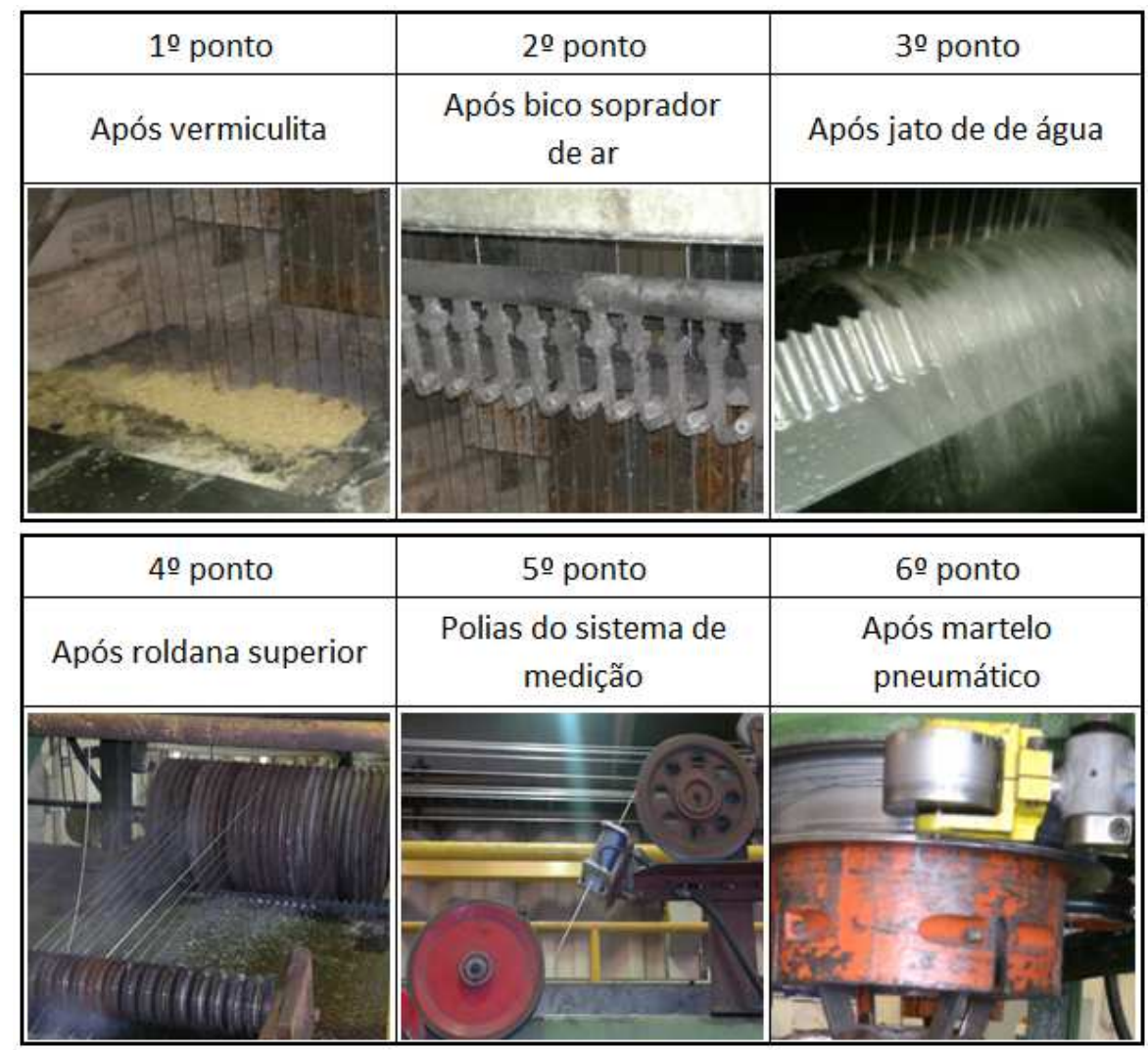

Figura 4. Posição de amostragem do arame nas etapas do processo de galvanização

\subsection{Velocidades de Processo na 1a e $2^{\text {a }}$ Passada e Resultado de Preece}

Nessa etapa do estudo foram produzidos arames galvanizados variando as velocidades da $1^{\underline{a}}$ e da $2^{\underline{a}}$ passada, avaliando o resultado de preece em cada caso. O objetivo é obter os parâmetros de processo para garantir mais de 6 imersões no ensaio de preece nos arames galvanizados classe B acima de $3,05 \mathrm{~mm}$. As velocidades variaram de $\mathrm{Y}$ a $6^{*} \mathrm{Ym} / \mathrm{min}$ e objetivaram formar quantidade de $\mathrm{Fe}-\mathrm{Zn}$ adequada para garantir proteção do arame como também atender a especificação de gramatura de zinco, sem excesso de sobrecamada.

\footnotetext{
* Contribuição técnica ao $69^{\circ}$ Congresso Anual da ABM - Internacional e ao 14ํㅡㄹ ENEMET - Encontro Nacional de Estudantes de Engenharia Metalúrgica, de Materiais e de Minas, 21 a 25 de julho de 2014, São Paulo, SP, Brasil.
} 


\section{RESULTADOS E DISCUSSÃO}

\subsection{Perfil das Camadas de Zn e Fe-Zn com a Velocidade na Galvanização}

A figura 5 nos permite visualizar o resultado de gramatura obtida quando a velocidade do arame foi elevada de $10 \mathrm{~m} / \mathrm{min}$ a $35 \mathrm{~m} / \mathrm{min}$.

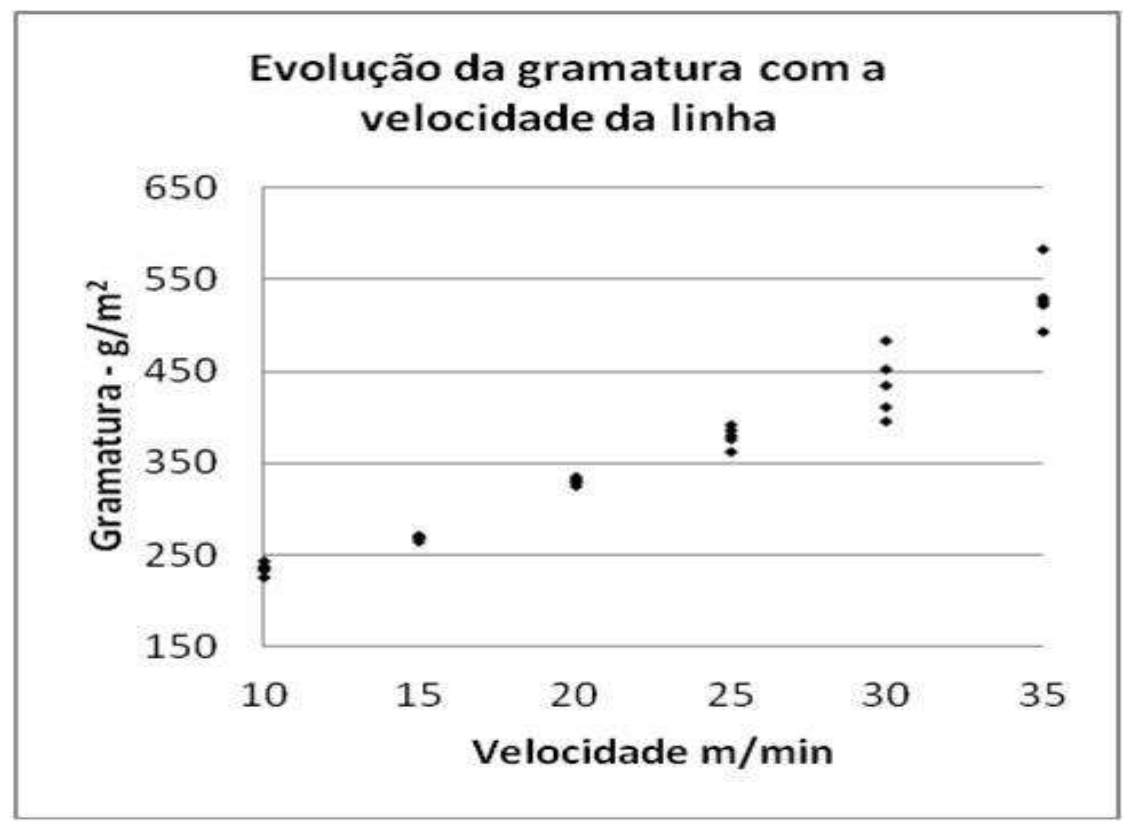

Figura 5. Aumento da gramatura em função da velocidade de extração

Por meio da figura 6 pode-se observar que a camada de zinco perde uniformidade à medida que a velocidade aumenta. Nas metalografias abaixo os arames foram avaliados nas velocidades de 10,20 e $30 \mathrm{~m} / \mathrm{min}$. Na figura 7, a amostra produzida com $20 \mathrm{~m} / \mathrm{min}$ foi avaliada com maior escala de ampliação, avaliando a uniformidade tanto da camada de zinco como de Fe-Zn.

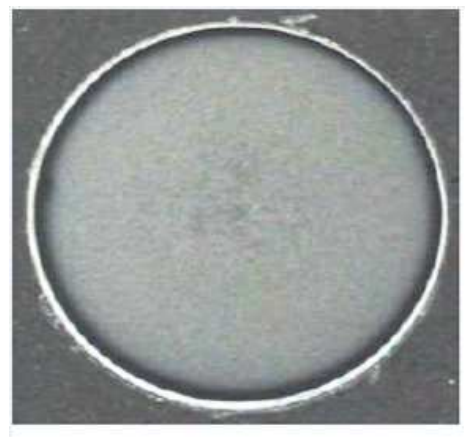

$10 \mathrm{~m} / \mathrm{min}$

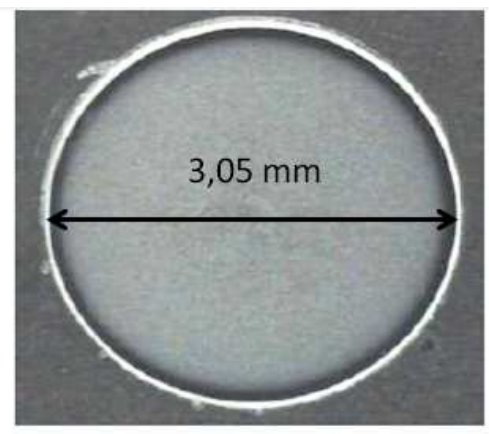

$20 \mathrm{~m} / \mathrm{min}$

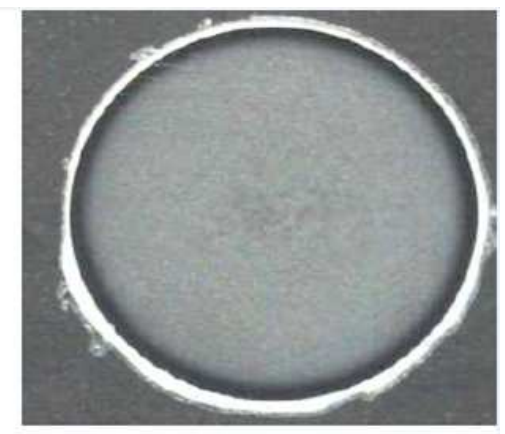

$30 \mathrm{~m} / \mathrm{min}$

Figura 6. Metalografia da secção transversal das amostras produzidas a 10, 20 e 30m/min

\footnotetext{
* Contribuição técnica ao 69ำ Congresso Anual da ABM - Internacional e ao 14ํㅡㄹ ENEMET - Encontro Nacional de Estudantes de Engenharia Metalúrgica, de Materiais e de Minas, 21 a 25 de julho de 2014, São Paulo, SP, Brasil.
} 


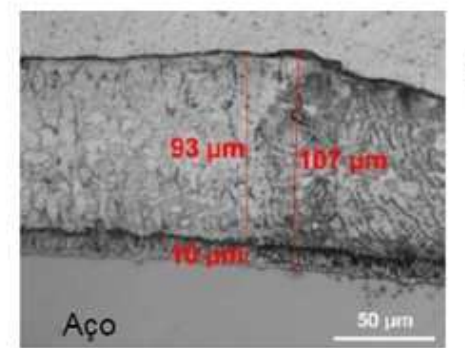

1
4

3
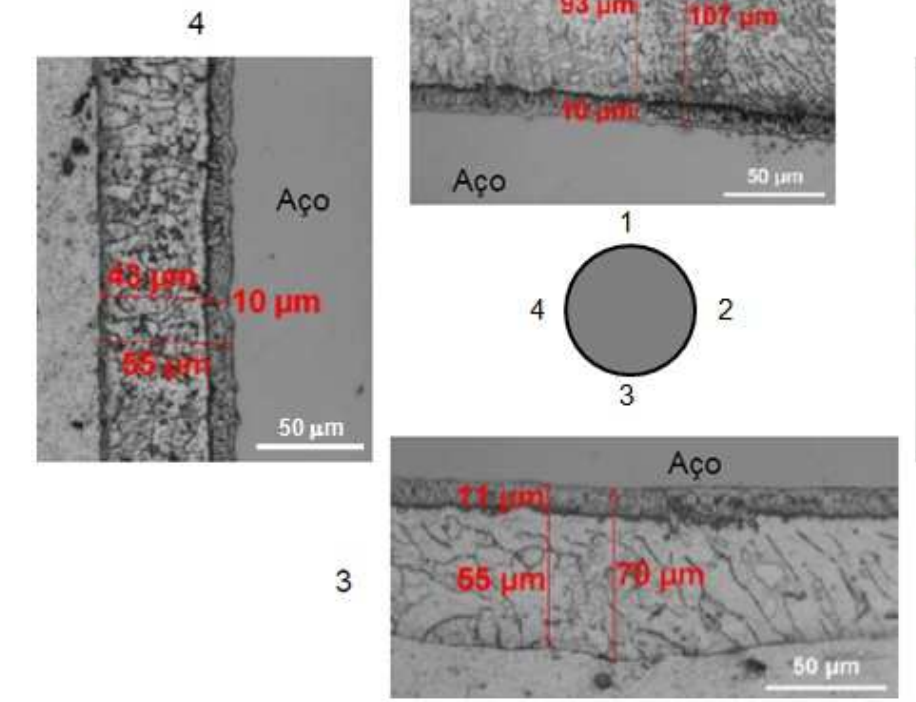

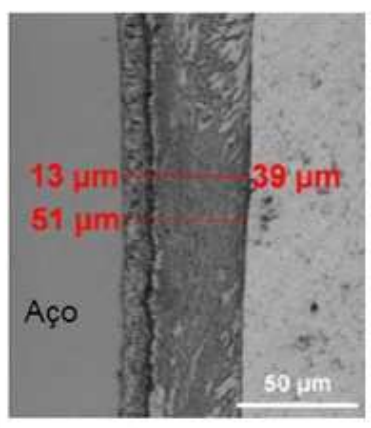

2

Figura 7. Metalografia da secção transversal da amostra produzida com $20 \mathrm{~m} / \mathrm{min}$

$\mathrm{Na}$ tabela 3 pode ser vista a espessura da camada de $\mathrm{Zn}$ e de Fe-Zn em cada uma das velocidades avaliadas. Observa-se que na medida em que a velocidade aumenta a camada de Fe-Zn reduz em função da redução do tempo de reação do zinco com o ferro no interior da cuba.

Tabela 3. Espessura das camadas de $\mathrm{Zn}$ e Fe-Zn com a velocidade

\begin{tabular}{cccccc}
\hline $\begin{array}{c}\text { Velocidade } \\
\mathbf{m} / \mathbf{m i n}\end{array}$ & $\begin{array}{c}\text { Total } \\
(\boldsymbol{\mu m})\end{array}$ & $\begin{array}{c}\text { Fe-Zn } \\
(\boldsymbol{\mu m})\end{array}$ & $\begin{array}{c}\mathbf{Z n} \\
(\boldsymbol{\mu m})\end{array}$ & Fe-Zn \% & $\begin{array}{c}\text { Total } \\
\left(\mathbf{g} / \mathbf{m}^{\mathbf{2}}\right)\end{array}$ \\
\hline 10 & 52,25 & 17,5 & 33,5 & 33,5 & 313 \\
\hline 20 & 70,75 & 11 & 57,5 & 15,5 & 430 \\
\hline 30 & 96,75 & 8,5 & 87,5 & 8,8 & 590 \\
\hline
\end{tabular}

É possível confirmar por meio desse experimento que a velocidade tem forte influência sobre a gramatura final do arame galvanizado e que ao aumentar a velocidade o desvio padrão da gramatura sobe de $8,2 \mathrm{~g} / \mathrm{m}^{2}(10 \mathrm{~m} / \mathrm{min})$ para $34,3 \mathrm{~g} / \mathrm{m}^{2}$ $(35 \mathrm{~m} / \mathrm{min})$. Outra constatação é que embora a quantidade de zinco cresça com a velocidade, a mesma perde a uniformidade.

\subsection{Crescimento da Camada de Fe-Zn com Pós-aquecimento}

No experimento realizado as amostras submetidas a um aquecimento em mufla não tiveram temperatura constante ao longo de todo o comprimento da amostra. Dessa forma não foi possível determinar a temperatura exata em cada ponto do arame. $\mathrm{Na}$ tabela 4 pode ser visto a espessura da camada de Fe-Zn, bem como o \% de Fe-Zn em cada posição.

\footnotetext{
* Contribuição técnica ao 69 Congresso Anual da ABM - Internacional e ao 14ํㅡㄹ ENEMET - Encontro Nacional de Estudantes de Engenharia Metalúrgica, de Materiais e de Minas, 21 a 25 de julho de 2014, São Paulo, SP, Brasil.
} 

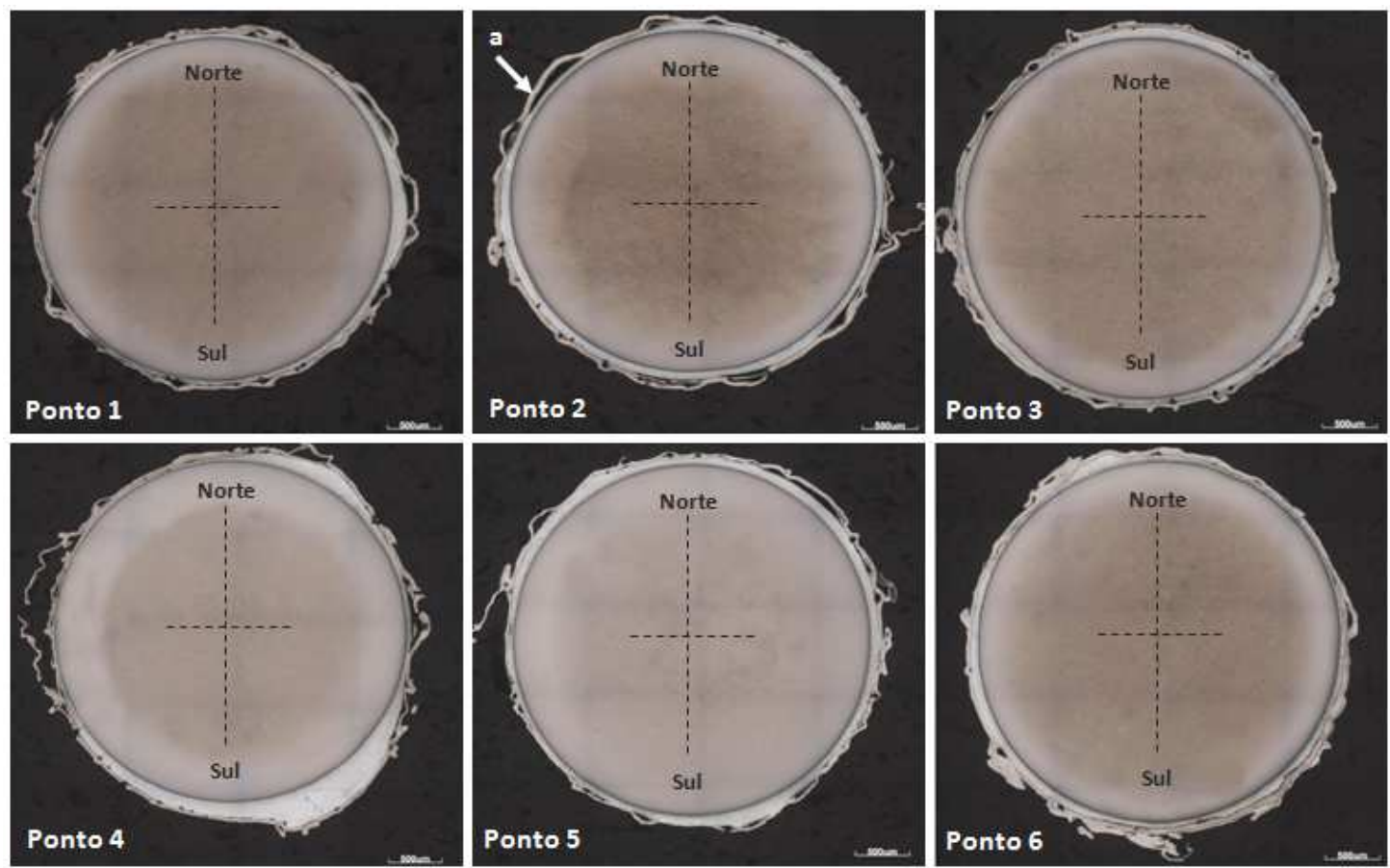

Figura 9. Metalografia da secção transversal dos arames em cada ponto de medição selecionado. Obs: O ponto 2 "a" exemplifica o papel alumínio utilizado no processo de embutimento das amostras. O papel alumínio é observado em todas as amostras e deve ser desconsiderado da análise.

\subsection{Velocidades da $1^{\mathrm{a}}$ e $2^{\mathrm{a}}$ Passada versus Resultado de Preece}

Inicialmente $300 \mathrm{~kg}$ de arame galvanizado foram produzidos na velocidade de $\mathrm{Ym} / \mathrm{min}$ e os outros $300 \mathrm{~kg}$ na velocidade de $2^{*} \mathrm{Ym} / \mathrm{min}$. Foram coletadas amostras desse material de forma a não comprometer o restante do produto. Das amostras retiradas, foi realizado ensaio de preece e os resultados são mostrados na tabela 5.

Tabela 5. Resultado de preece e gramatura nas velocidades de $\mathrm{Ym} / \mathrm{min}$ e $2^{*} \mathrm{Ym} / \mathrm{min}$ na $1^{\underline{a}}$ passada

\begin{tabular}{ccccc}
\hline & \multicolumn{2}{c}{ Velocidade Ym/min } & \multicolumn{2}{c}{ Velocidade 2*Ym/min } \\
\hline Amostra & Preece & $\begin{array}{c}\text { Gramatura } \\
\left(\mathbf{g} / \mathbf{m}^{2}\right)\end{array}$ & Preece & $\begin{array}{c}\text { Gramatura } \\
\left(\mathbf{g} / \mathbf{m}^{2}\right)\end{array}$ \\
\hline 1 & 5 & 294 & 4 & 443 \\
\hline 2 & 5 & 313 & 4 & 303 \\
\hline 3 & 5 & 311 & 4 & 309 \\
\hline 4 & 5 & 300 & 4 & 291 \\
\hline 5 & 5 & 307 & 4 & 298 \\
\hline 6 & 5 & 330 & 4 & 289 \\
\hline 7 & 5 & 298 & 4 & 307 \\
\hline Média & $\mathbf{5}$ & $\mathbf{3 0 7 , 6}$ & $\mathbf{4}$ & $\mathbf{3 2 0 , 0}$ \\
\hline
\end{tabular}

É possível constatar que os resultados de gramatura obtidos na velocidade da $1^{\underline{a}}$ passada nas amostras com velocidade de $\mathrm{Ym} / \mathrm{min}$ foi superior ao obtido com $2^{*} Y \mathrm{~m} / \mathrm{min}$, não havendo diferença significativa de média. Posteriormente foi realizada a segunda etapa do teste, repassando o material com velocidade inicial de $\mathrm{Ym} / \mathrm{min}$ a $2 \mathrm{Y}, 4 \mathrm{Y}$ e $6 \mathrm{Ym} / \mathrm{min}$. Os resultados obtidos podem ser vistos na tabela 6 e

\footnotetext{
* Contribuição técnica ao $69^{\circ}$ Congresso Anual da ABM - Internacional e ao 14ํㅡㄹ ENEMET - Encontro Nacional de Estudantes de Engenharia Metalúrgica, de Materiais e de Minas, 21 a 25 de julho de 2014, São Paulo, SP, Brasil.
} 
demonstram que apesar da grande diferença em gramatura, não houve diferença significativa das médias de resultado de preece.

Tabela 6. Resultado de preece e gramatura nas velocidades de $2 \mathrm{Y}, 4 \mathrm{Y}$ e $6 \mathrm{Ym} / \mathrm{min}$ na $2^{\mathrm{a}}$ passada

\begin{tabular}{cccccc}
\hline $\begin{array}{c}\text { Velocidade } \\
\mathbf{1}^{\circ} \text { pass } \\
(\mathbf{m} / \mathbf{m i n})\end{array}$ & $\begin{array}{c}\text { Velocidade } \\
\mathbf{2}^{\circ} \text { pass } \\
\mathbf{( m / m i n )}\end{array}$ & \multicolumn{2}{c}{ Preece } & \multicolumn{2}{c}{$\begin{array}{c}\text { Gramatura } \\
\mathbf{g} / \mathbf{m}^{\mathbf{2}}\end{array}$} \\
\cline { 3 - 6 } & $2 \mathrm{Y}$ & 6,1 & 0,6 & 462,2 & 10,2 \\
\hline $\mathrm{Y}$ & $4 \mathrm{Y}$ & 6,8 & 0,7 & 608,8 & 11 \\
\hline $\mathrm{Y}$ & $6 \mathrm{Y}$ & 7 & 0,6 & 773,8 & 11,8 \\
\hline $\mathrm{Y}$ & & & & &
\end{tabular}

Como não houve diferença significativa entre o resultado de preece das amostras produzidas com $4^{*} \mathrm{Ym} / \mathrm{min}$ e $6^{*} \mathrm{Ym} / \mathrm{min}$ (embora a variação de gramatura tenha sido da ordem de $165 \mathrm{~g} / \mathrm{m}^{2}$ ) optou-se por padronizar a produção do material na velocidade de $4^{\star} \mathrm{Ym} / \mathrm{min}$ a fim de minimizar as perdas de zinco por sobrecamada, visto que 0 especificado para este material é de $520 \mathrm{~g} / \mathrm{m}^{2}$ conforme tabela1.

\section{CONCLUSÃO}

A partir desse trabalho foi possível verificar que a velocidade da linha de galvanização tem forte influência sobre o arraste de zinco. Os estudos mostraram que com velocidade acima de $20 \mathrm{~m} / \mathrm{min}$ tem-se arraste excessivo de zinco, com perda de uniformidade da camada e redução da espessura da camada de Fe-Zn. Também foi possível verificar que mantendo a temperatura do arame após a cuba 0 processo de crescimento da camada de Fe-Zn pode continuar, aumentando-se a resistência no ensaio de preece.

Os testes no processo mostraram que é possível produzir o arame galvanizado classe $B 3,05 \mathrm{~mm}$ com processo de duas passadas pela cuba de zinco. A primeira passada foi realizada a Ym/min (favorecendo o crescimento da camada de Fe-Zn) e a segunda a $4^{*} \mathrm{Ym} / \mathrm{min}$ (objetivando o atendimento da gramatura e uniformidade da camada). Com esses parâmetros, obteve-se êxito no ensaio de preece (6 imersões). Por fim, verificou-se que embora a roldana superior estivesse deslocando a camada de zinco por amassamento, os pontos de contato posteriores acabavam por uniformizar a camada de zinco.

\section{Agradecimentos}

Gostaria de agradecer inicialmente ao Gerente de Tecnologia de Processos e Produtos da Gerdau Aços Brasil Leonardo Braga Polido Lopes pela oportunidade de apresentar este trabalho em um fórum tão prestigiado como a ABM. Gostaria também de agradecer ao consultor da Gerdau Jorge Adam Cleto Cohn pela valorosa e imprescindível contribuição técnica no desenvolvimento deste trabalho. Por fim, agradeço aos meus colegas de trabalho Cristiano Terres Monteiro, Luciana de Carvalho Affonso, Marcelo Girotto de Mattos e Tiago Nisio Gonçalves que contribuíram na revisão e execução deste trabalho.

\footnotetext{
* Contribuição técnica ao $69^{\circ}$ Congresso Anual da ABM - Internacional e ao 14ํㅡㄹ ENEMET - Encontro Nacional de Estudantes de Engenharia Metalúrgica, de Materiais e de Minas, 21 a 25 de julho de 2014, São Paulo, SP, Brasil.
} 


\section{REFERÊNCIAS}

1 ABNT NBR 7400:2009 - Produto de aço ou ferro fundido revestido de zinco por imersão a quente - Verificação da uniformidade do revestimento. p. 1 - 4.

2 ABNT NBR 6756:2007 - Fios de aço zincados para alma de cabos de alumínio e alumínio-liga - Especificação. p. 1 - 9.

3 Campanher CG. Otimização experimental em processo de galvanização de arames de camada pesada. UFRG. Porto Alegre, RS (2009) p.1 - 97.

4 Groesbeck EE, Walkup HH. Preece Test (cooper-sulphate dip) for Zinc Coatings. Part of Bureau of Standards Journal of Research, vol. 12, June 1934, p. 785 - 802E.

5 Gracia Jr L, Mallet A. Curso de Galvanização do Grupo Gerdau. 1985, 1989, 1993.

6 Marder AR. The metallurgy of zinc-coated steel. Progress in Materials Science, p. $193-$ 213, 2000. Progress in Materials Science, 2000; 45: 191 - 271.

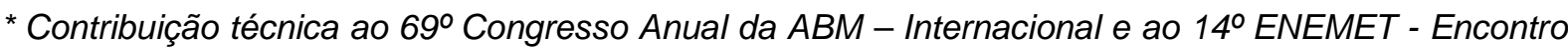
Nacional de Estudantes de Engenharia Metalúrgica, de Materiais e de Minas, 21 a 25 de julho de 2014, São Paulo, SP, Brasil. 